ISSN: 2644-1217

\title{
Tips for Grandparents
}

\author{
Uqbah Iqbal*, Ahmad J, and Hj SR, Idris and Zakaria S
}

Life Planner, School of History, Kuala Lumpur, Malaysia

Received: 业 October 10, 2018; Published: 海 October 17, 2018

*Corresponding author: Uqbah Iqbal, Life Planner, School of History, Suite P4, Level 31, AIA Cap Square Tower, Jalan Munshi Abdullah, 50100 Golden Triangle, Kuala Lumpur

\section{Opinion}

The lives of traditional Malays are always circled with various incidents that can cause a person to experience various diseases. A disease can be cured through medical methods. Since disease can be avoided, Malay credentials believe there are several ways in which the disease can be avoided. Hence, there are some tips that allow the Malay community to practice the tips to achieve a better life. In traditional Malay medicine, the use of many tips is practiced. Tips are not only used for treating ailments but have many other functions. Tips are often used for the purpose of maintaining a personal beauty, a taste of cuisine and so on. The tips used by ordinary Malaysians use the many herbs that grow in the area of the home. Knowledge of this herbaceous plant can be used as a cure for illness. Therefore, the use of herbs in the tips is widespread. Tips are derived from one generation to one generation. Practical delivery is often done to facilitate a new generation of practicing the tips. Hence, one does not need a detailed study on the use of herbs but is sufficiently illustrated by the previous generation either in the village community or in the city. In everyday life, there are just new tips.

The history of the practice of hints is still unknown because there is no clear evidence of the fact that since humans have practiced hints. But what can be said, tips have been around since people began to know the importance of tips. In the past man was exposed to all dangers. Animism and Hindu influence have led the local community to believe every place they want to explore has certain powers such as a waiter or a ghost. These powers if not presented with a presentation will cause a person to get the spread of the disease. Therefore, the community has already created a tip that is used to protect themselves from harm. Then after people are attacked by a variety of diseases, they are trying to maintain their health. Because they are susceptible to various diseases, preventive measures have been implemented. Hence, many herbs have been used as a cure for diseases. The effectiveness of tips in life has led people to create some tips on how to look after their own beauty. These tips are widely practiced by women to look always beautiful and interesting. In addition, the tips can also make a person healthy. Tips keep on changing and not only focusing on body care but covers all aspects of everyday life.

Before the Malay community embraced Islam, the influence of animism and Hinduism was so thick. The influence of this belief enabled some of the beliefs that led the Malays to fear and want protection. The beliefs of animism believe that every place they want to explore has many external elements such as waiter, pod or ghost. They also believe these elements will cause a striker to attack someone. Therefore, the Malay community has been looking for a way to avoid the illness that may be present. Hence, they have found some tips that intend to give the waiter. Among the tips that are still practiced today are to tear down homes or dwellings so that family members living there will not get any harm or illness. After the advent of Islam, the belief in such elements is diminishing. The Malay community began to believe that every illness was the result of an unhealthy body that either did not care for our own health or there were external elements such as weather or infection. Therefore, the Malay community has begun to create some tips to keep yourself healthy. Then the use of tips continues to be expanded and not just a matter of health. 
(C) (i) This work is licensed under Creative Commons Attribution 4.0 License

To Submit Your Article Click Here:

Submit Article

DOI: 10.32474/OAJCAM.2018.01.000106

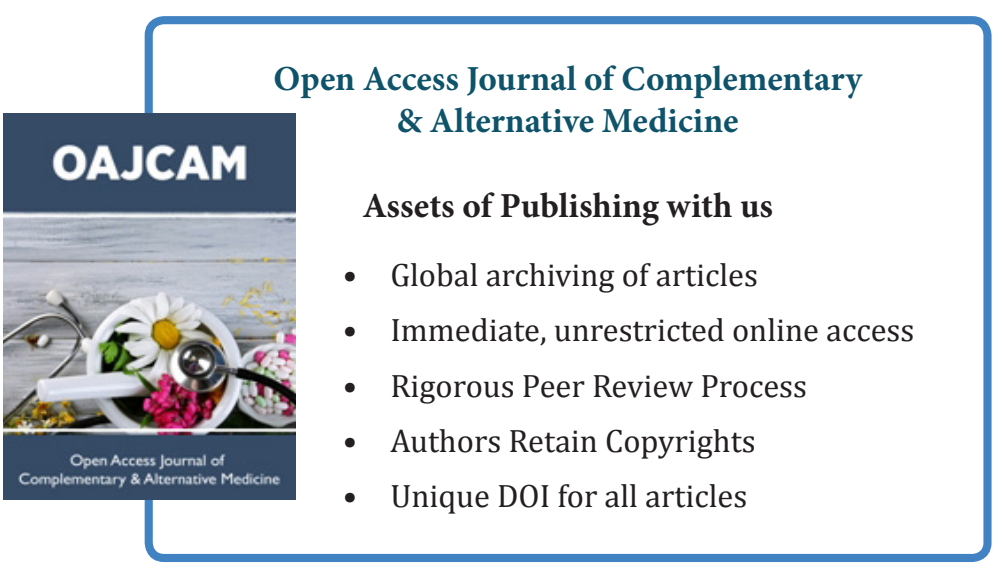

